\title{
Helicobacter pylori, gastritis, and peptic ulceration in the elderly
}

\author{
J I Wyatt, T M Shallcross, J E Crabtree, R V Heatley
}

\begin{abstract}
Aims: To determine the histopathological types of gastritis, presence of $H$ pylori, and of peptic ulceration in patients aged 70 and over, compared with younger adults.

Methods: Gastric antral and corpus biopsy specimens from 112 elderly patients were classified and graded histologically according to the Sydney system. Details of recent antibiotic and non-steroidal anti-inflammatory drug use were recorded. Eighty four of the patients were positive for $H$ pylori IgG antibodies and parietal cell antibodies. The results were compared with those from a series of 124 adult patients aged under 60 .
\end{abstract}

Results: $H$ pylori were visible at histological examination in only 57 of 87 $(65 \cdot 5 \%)$ elderly patients with chronic gastritis (excluding "special forms") compared with 72 of $79(91 \cdot 1 \%)$ of the younger patients with gastritis $(p<0.0002)$. Severe atrophy of the corpus mucosa was significantly associated with absence of $H$ pylori $(\mathrm{p}<0.002)$, and was present in eight of 30 elderly patients with helicobacter negative gastritis. Other explanations for absence of $\boldsymbol{H}$ pylori include recent antibiotic intake, more intestinal metaplasia, and lower bacterial load in elderly patients $(p<0.05)$. Autoimmune gastritis and NSAID use did not seem to be relevant. Serodiagnosis showed reduced sensitivity $(81 \%)$ in patients who were helicobacter positive histologically, but was positive in 14 of $23(61 \%)$ with $H$ pylori negative gastritis histologically, suggesting either current infection that had been missed or previous infection. Peptic ulceration was significantly associated with NSAID use, but not with $H$ pylori in the elderly.

Conclusions: The spectrum of gastritis is different in the elderly, compared with younger adults, due to a significant group with chronic gastritis who are $H$ pylori negative on histological examination. NSAID use, but not demonstration of $H$ pylori (at histological examination) is associated with peptic ulceration in the elderly.

\section{(F Clin Pathol 1992;45:1070-1074)}

The prevalence of chronic gastritis is well known to increase with age, and to become so common in older subjects as to be considered a "normal" ageing phenomenon. ${ }^{1}$ Infection with
$H$ pylori probably accounts for most cases of "non-specific" chronic gastritis, ${ }^{2}$ and the prevalence of $H$ pylori in adult populations increases with age, in parallel with that of chronic gastritis. ${ }^{34}$ However, most such studies of prevalence, based on blood donor serology, include few if any subjects over 60 years of age. It was our impression that while over $90 \%$ of adult patients under 60 with gastritis were infected with $H$ pylori (detected at histological examination), the association was considerably less strong in the elderly.

Recent classifications subdivide chronic gastritis, where possible, along aetiological or pathogenetic lines. ${ }^{5}$ The Sydney system for the classification of chronic gastritis (proposed at the World Congresses of Gastroenterology, Sydney, 1990) recognises acute, chronic, and special forms of chronic gastritis, permitting separation of distinct entities previously grouped together as chronic gastritis. ${ }^{7}$ The aim of this study was to determine the different types of gastritis present in a series of patients aged 70 and over undergoing routine endoscopy, and to compare these with the pattern of gastritis seen in younger adults, with particular reference to $H$ pylori negative chronic gastritis and its possible causes.

\section{Methods}

Over an eight month period consecutive and unselected patients aged 70 and over, undergoing routine upper gastrointestinal endoscopy in one unit, were studied. Patients who had undergone previous gastric surgery, and those undergoing therapeutic endoscopy, were excluded. One mucosal biopsy specimen was taken from the gastritis antrum within $20 \mathrm{~mm}$ of the pylorus, and another was taken from the greater curve opposite the oesophageal opening.

Details of recent use of antibiotics and nonsteroidal anti-inflammatory drugs (NSAIDs) were obtained from the clinical records and, were possible, by direct questioning. Adequate biopsy specimens from both sites were available from a total of 112 patients (aged 70-95 years, mean 80.25 years, 40 male) out of a possible $151(74 \%) ; 18$ patients were excluded because of inadequate biopsy specimens, and the remainder because of other technical difficulties.

For comparison, endoscopic biopsy specimens (from gastric antrum and corpus) from 124 consecutive patients aged 16-60 years (mean 43.8 years, 55 male), attending a dyspepsia clinic, were studied. All studies were approved by the local hospital ethics committee. 
Table 1 Different types of gastritis in patients of different age groups

\begin{tabular}{lcc}
\hline & $\begin{array}{c}\text { Patients }>70 y \\
(n=112)\end{array}$ & $\begin{array}{l}\text { Patients }<60 y \\
(n=124)\end{array}$ \\
\hline Normal & $12(10 \cdot 7 \%)$ & $33(26 \cdot 6 \%)$ \\
Acute gastritis & 0 & 0 \\
Reactive gastritis & $11(9 \cdot 8 \%)$ & $11(8.9 \%)$ \\
Lymphocytic gastritis & $2(1.8 \%)$ & $1(0 \cdot 8 \%)$ \\
Chronic gastritis: & $87(77 \cdot 7 \%)$ & $79(63.7 \%)$ \\
$\quad H$ pylori positive & $57(50.9 \%)$ & $72(58 \cdot 1 \%)$ \\
no H pylori seen & $30(26.8 \%)$ & $7(5.6 \%)$ \\
\hline
\end{tabular}

Serum was obtained before endoscopy and stored at $-20^{\circ} \mathrm{C}$. $H$ pylori $\mathrm{IgG}$ antibodies were measured by ELISA using an antigen prepared from one strain of $H$ pylori, as described before. ${ }^{89}$ Parietal cell antibodies were detected by indirect immunofluorescence using a mouse stomach substrate, and intrinsic factor blocking antibodies by solid phase ${ }^{57} \mathrm{Co}-$ radioimmunoassay (Diagnostic Products Corporation, Los Angeles, USA).

Gastric biopsy specimens were routinely processed, and sections stained by haematoxylin and eosin, alcian blue/periodic acid Schiff for intestinal metaplasia, and Giemsa ${ }^{10}$ for detection of $H$ pylori. Antral and corpus mucosal biopsy specimens were classified according to the Sydney system by one pathologist for the type of gastritis (normal, acute, chronic, or special forms including reactive and lymphocytic). The mucosal features of chronic inflammation, neutrophil infiltration (activity), atrophy, intestinal metaplasia and $H$ pylori density were graded on a scale of $0-3$ for each biopsy specimens according to the Sydney system. Chronic gastritis, which affected both antrum and corpus, was classified as antrum or corpus predominant, according to the respective degrees of inflammation and atrophy, or as pangastritis when antrum and corpus showed similar severity. ${ }^{7}$

Comparison between patient groups was done by the $\chi^{2}$ or Fisher's exact two-tailed tests, and results considered significant if $\mathrm{p}<$ 0.05 .

\section{Results}

CHRONIC GASTRITIS

The prevalence of normal mucosa, chronic gastritis, and special forms of gastritis in the two age groups is shown in table 1. Acute gastritis was not seen in any patient in either series. Among the younger patients the incidence of $\mathrm{H}$ pylori increased with age, from nine of $34(37 \%)$ in the under-30s to 33 of 49 $(67 \%)$ in patients aged $51-60$.

The histological features of reactive gastritis $^{11}$ were seen in 11 of 112 of the elderly

Table 2 Distribution of chronic gastritis (excluding lymphocytic and reactive gastritis)

\begin{tabular}{|c|c|c|c|c|}
\hline & \multicolumn{2}{|c|}{ Patients $>70 y$} & \multicolumn{2}{|c|}{ Patients $<60 y$} \\
\hline & $\begin{array}{l}H \text { pylori } \\
\text { positive }\end{array}$ & $\begin{array}{l}H \text { pylori } \\
\text { negative }\end{array}$ & $\begin{array}{l}H \text { pylori } \\
\text { positive }\end{array}$ & $\begin{array}{l}H \text { pylori } \\
\text { negative }\end{array}$ \\
\hline Antrum only & 5 & 1 & 7 & 1 \\
\hline Antrum predominant & 11 & 4 & 9 & 0 \\
\hline Corpus only & 2 & 4 & 0 & 3 \\
\hline Corpus predominant & 2 & 5 & 0 & 0 \\
\hline Pangastritis & 37 & 16 & 56 & 3 \\
\hline Total & 57 & 30 & 72 & 7 \\
\hline
\end{tabular}

patients and in 11 of 124 of those under 61 ; all were $H$ pylori negative. This pattern has been related to mucosal injury caused by NSAIDs, alcohol misuse, or bile reflux in previous studies $^{11}$; in the elderly group, five of 11 patients with reactive gastritis had been taking NSAIDs during the previous month, and seven had a peptic ulcer at endoscopy, (five gastric, one duodenal, one at both sites). In the younger group five of 11 patients had recently used NSAIDs, of whom three had peptic ulcers (two gastric, one duodenal).

Lymphocytic gastritis ${ }^{12}$ was seen in two elderly and one young patient; all three cases were $H$ pylori negative histologically, although they were all seropositive for $H$ pylori.

Helicobacter-associated gastritis was present in $57(50.9 \%)$ of elderly patients and in 72 $(58 \cdot 1 \%)$ of patients under 60 years old. However, the prevalence of chronic gastritis without $H$ pylori infection at histological examination was significantly higher in the elderly (30 of 112 , or $26.8 \%$ ) than the younger patients (seven of 124 , or $5.6 \%)(p<0.0001)$. The characteristics of the group of elderly patients with $H$ pylori negative chronic gastritis were therefore compared with those with $H$ pyloriassociated gastritis to identify features related to histological negativity for $H$ pylori.

DISTRIBUTION OF GASTRITIS

Table 2 shows the distribution of inflammation in patients with $H$ pylori positive and negative chronic gastritis. Nine out of $30(30 \%)$ heliobacter-negative patients had gastritis which was more severe in the corpus, while only four of $57(7 \%) \mathrm{H}$ pylori positive patients showed this distribution of gastritis $(p=0.01)$. The Sydney system specifically comments on the presence of severe atrophy in gastric biopsy specimens. This feature was seen in corpus biopsy specimens from eight of $30(27 \%)$ of patients with $H$ pylori negative gastritis, but in only one of $57(2 \%)$ of those in whom $\mathrm{H}$ pylori was seen $(p<0.002)$. There was no significant difference between the prevalence of severe atrophy of the antral mucosa in the $H$ pylori negative group (nine of 30, three of whom also had severe atrophy of the corpus mucosa) and that of the $H$ pylori positive group (nine of 57, none with severe corpus atrophy).

SITUATIONS IN WHICH H PYLORI MIGHT BE MISSED BY HISTOLOGY

Intestinal metaplasia

$H$ pylori only attaches to gastric-type surface epithelium, and therefore biopsy specimens showing extensive intestinal metaplasia may lead to false negative histological diagnosis of $H$ pylori. Intestinal metaplasia was seen in at least one biopsy specimen from 17 of 30 (56\%) patients with helicobacter negative gastritis compared with 24 of 57 (42\%) patients with $H$ pylori positive gastritis. Intestinal metaplasia was extensive (graded 2 or 3 on the Sydney system) in one biopsy specimen from $13(23 \%)$ and nine $(30 \%)$ of the $H$ pylori positive and negative patients, respectively. Only one patient, who was $H$ pylori negative, had extensive intestinal metaplasia in both biopsy speci- 
Table 3 Prevalence of $H$ pylori (detected by histology) and use of NSAIDs in younger and elderly patients with and without peptic ulceration

\begin{tabular}{lclll}
\hline & $\begin{array}{l}\text { H pylori } \\
\text { negative, } \\
\text { no NSAIDs }\end{array}$ & $\begin{array}{l}\text { H pylori } \\
\text { positive, } \\
\text { no NSAIDs }\end{array}$ & $\begin{array}{l}\text { H pylori } \\
\text { negative, } \\
\text { taking NSAIDs }\end{array}$ & $\begin{array}{l}\text { H pylori } \\
\text { positive, } \\
\text { taking NSAIDs }\end{array}$ \\
\hline Age $<60$ no ulcer $\mathrm{n}=91$ & $34(37 \%)$ & $34(37 \%)$ & $11(12 \%)$ & $12(13 \%)$ \\
Age $<60$ peptic ulcer $\mathrm{n}=33$ & $2(6 \%)$ & $15(45 \%)$ & $5(15 \%)$ & $11(33 \%)$ \\
Age $>70$ no ulcer $\mathrm{n}=82$ & $28(34 \%)$ & $32(39 \%)$ & $12(15 \%)$ & $10(12 \%)$ \\
Age $>70$ peptic ulcer $\mathrm{n}=30$ & $7(23 \%)$ & $4(13 \%)$ & $8(27 \%)$ & $11(37 \%)$ \\
\hline
\end{tabular}

mens. These differences in intestinal metaplasia between the two groups were not significant.

Low density of $H$ pylori colonisation

$H$ pylori may be missed by histological examination when the bacterial density is low and the organisms patchily distributed. Among the elderly with $H$ pylori infection the proportion of antral biopsy specimens falling into grades 1,2 , and 3 for $H$ pylori density was $32 \%, 48 \%$ and $20 \%$, respectively, compared with $14 \%$, $54 \%$, and $32 \%$ in the younger patients $(\mathrm{p}<$ $0 \cdot 05)$.

\section{Drug use}

Four out of 30 (13\%) of the elderly group with $H$ pylori negative gastritis were known to have used antibiotics which might have resulted in suppression or eradication of $H$ pylori within the last month, compared with four of $57(7 \%)$ of those with $H$ pylori positive gastritis and three $(12 \%)$ of those with normal or reactive gastritis (differences not significant). None of the patients was known to have taken bismuth preparations.

Seven out of $30(23 \%)$ of those with $H$ pylori negative gastritis and 22 of 57 (39\%) of those with $H$ pylori positive gastritis had recently used NSAIDs (differences not significant).

\section{Peptic ulcers}

Thirty of the 112 elderly patients had benign peptic ulcers; 18 patients had gastric ulcers, eight had duodenal ulcers, and four had gastric and duodenal ulcers. Two patients had gastric

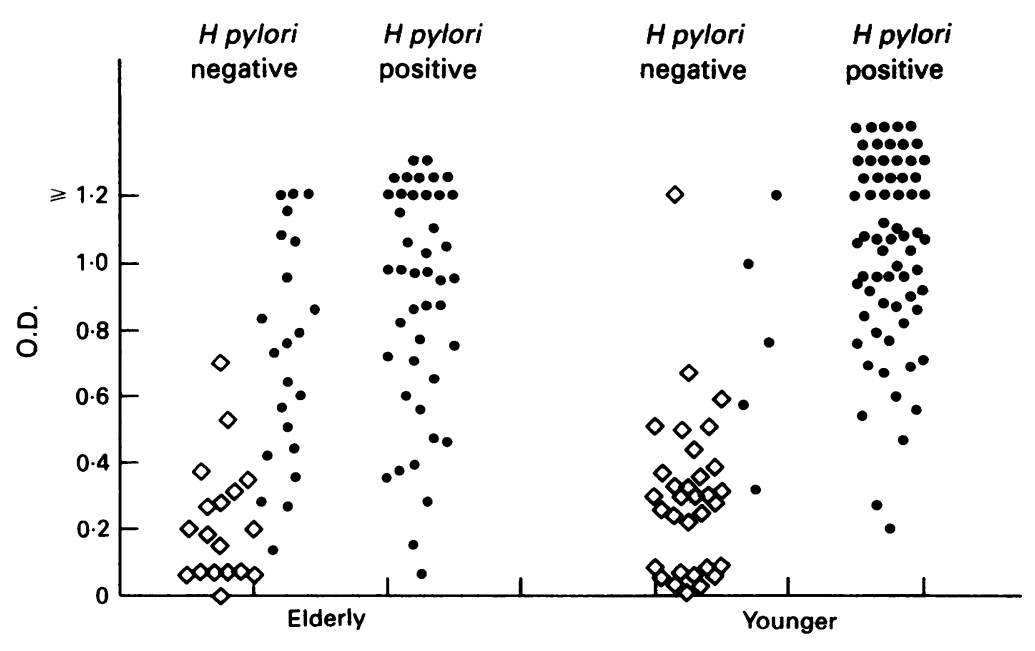

$\checkmark$ No gastritis - Gastritis

Correlation between gastritis, histological $H$ pylori status, and ELISA optical density in elderly patients $(n=84)$ and young patients $(n=103)$. cancer. The distribution of peptic ulcers in the elderly was significantly different from that seen in the 33 younger patients with peptic ulcer, of whom 12 had gastric ulcer, 20 duodenal ulcer, and one gastric and duodenal ulcer $(p<0.02)$.

There were also significant differences in the risk factors for peptic ulcer. Table 3 shows the incidence of $H$ pylori (detected by histological examination) and use of NSAIDs in the elderly patients with and without ulcers compared with the younger group. The association of $H$ pylori with ulceration in the younger group was not seen in the elderly, where the incidence of histologically detectable $H$ pylori was very similar in the ulcer and non-ulcer groups. Peptic ulceration in the absence of $H$ pylori was significantly more common in the elderly group (15 of $30 v$ seven of 33; p < 0.05); eight of these patients had been taking NSAIDs, and 11 of the $15 \mathrm{H}$ pylori positive elderly patients with ulceration were also taking NSAIDs. Seven $(23 \%)$ of the elderly patients with ulcers had neither risk factors (although all but two had chronic gastritis), compared with only two of $33(6 \%)$ of the younger group.

SEROLOGY

Serum was available from 84 of the elderly patients and 103 of the younger group. The correlation between gastritis, histological $H$ pylori status, and ELISA optical density in the $H$ pylori IgG ELISA is shown in the figure. For this purpose, patients with reactive gastritis have been placed in the "no gastritis" group, because this special category of gastritis does not show an inflammatory cell infiltrate in the mucosa, and the three patients with lymphocytic gastritis have not been included. In the elderly group $H$ pylori serology is much less useful as a predictor of histological $H$ pylori status than in the younger group, with a number of patients who were histologically positive but with low antibody titres, and a large group of histologically negative patients who had high antibody titres. Of those who were histologically negative but seropositive (OD > 0.53), all but one had chronic gastritis.

Parietal cell antibodies were detected in nine of 84 elderly patients from whom serum was available; titres were low $(1 / 10)$ in six of these positive patients. Five of the parietal cell antibody positive patients had helicobacter associated gastritis, two had helicobacter negative gastritis, and two were histologically normal. Only one parietal cell antibody positive patient had histological evidence characteristic of autoimmune gastritis (corpus predominant, helicobacter negative chronic gastritis) and this patient was also seropositive for $H$ pylori. Serum samples from 16 patients with helicobacter negative chronic gastritis were also tested for intrinsic factor antibodies, but all were seronegative.

\section{Discussion}

In this study we have shown that the spectrum of chronic gastritis in the elderly differs from that in younger adults: specifically, that there is 
a group with chronic gastritis in whom $H$ pylori is not detectable by histological examinationan unusual occurrence in younger subjects, where in our experience $e^{1314}$ and that of others, ${ }^{15}$ over $90 \%$ of chronic gastritis is associated with $H$ pylori infection. Although the group of younger patients in our study were attending a dyspepsia clinic, we have found no difference in their prevalence of gastritis nor $H$ pylori status compared with a consecutive series of patients of the same age undergoing "routine" endoscopy.

There are at least three possible reasons for the higher prevalence of $H$ pylori negative gastritis in the elderly. First, $H$ pylori could have been present but in small numbers which might not have been detected by histological examination. Secondly, $H$ pylori could have been present in the past but was eliminated, either by antibiotics, or because the gastric environment no longer suited its growth requirements. The third possibility is that $H$ pylori was never present-that the gastritis in these patients had a different aetiology, such as autoimmune gastritis or as a result of ingestion of NSAIDs, both of which might be expected in the elderly population.

The histological arm of the Sydney system was used in our study as a basis for comparison of the various types of gastritis between younger and elderly patients. The prevalence of the "special forms" of reactive and lymphocytic gastritis was similar in the different age groups, while no cases of acute gastritis or other special forms, such as granulomatous or eosinophilic gastritis, were seen in this study. Thus the reduction in $H$ pylori positivity among patients with chronic gastritis (excluding special forms) constituted the main difference in the elderly patients.

In our experience histological examination is the most sensitive biopsy based technique for detecting $H$ pylori compared with culture ${ }^{14}$ or the CLO test. ${ }^{16} \mathrm{We}^{16}$ and others ${ }^{17}$ have found that taking two biopsy specimens largely eliminates sampling error, except in patients with very low bacterial load in whom it will be difficult to detect $H$ pylori by many techniques. ${ }^{18}$ Among the elderly patients, however, the increased prevalence of intestinal metaplasia and the reduced bacterial density in non-metaplastic areas of the biopsy specimen may both contribute to a reduced sensitivity of histology for $H$ pylori detection.

It has been suggested that severe atrophy of the corpus mucosa represents the "end stage" of Helicobacter associated chronic gastritis, and that as the degree of atrophy increases, current overt infection declines. ${ }^{19}$ Our results are consistent with this hypothesis, as we found $H$ pylori in only one of nine patients with severe atrophy of the corpus. Although autoimmune chronic gastritis typically affects the corpus mucosa, most of our patients with gastritis, predominantly of the corpus mucosa, did not have gastric autoantibodies. In a study of pernicious anaemia by Feng et al, ${ }^{20}$ positive serology but negative biopsy results for $H$ pylori were found in five of 28 patients, suggesting that in some cases pernicious anaemia may be a late effect of $H$ pylori infection, as suggested by de Luca. ${ }^{21}$ Other conditions of hypochlorhydria (following partial gastrectomy, ${ }^{22}$ or omeprazole treatment) ${ }^{23}$ are also associated with a reduced prevalence of $H$ pylori, suggesting that some degree of acid secretion is necessary for $H$ pylori to persist in the gastric environment.

In agreement with our previous findings, ${ }^{13}$ and in contrast with those of O'Riordan et al, ${ }^{24}$ this study does not support the hypothesis that NSAIDs are a cause of $H$ pylori negative gastritis, with similar prevalence of NSAID use in those with $H$ pylori positive and negative gastritis.

We have previously found a high sensitivity and specificity for serodiagnosis of $H$ pylori by ELISA, especially in children ${ }^{9}$ and adults under 61 years. $^{25}$ However, among elderly patients with gastritis there were both false negative and false positive results, when compared with histological examination, for $H$ pylori. The reduced sensitivity of ELISA in this study (only $81.4 \%$ of elderly patients with $H$ pylori on histological examination were seropositive) may reflect a general decline of immune function with age. ${ }^{26}$ Conversely, the presence of $H$ pylori antibodies in $67 \%$ of the patients with $H$ pylori negative gastritis on histological examination could be due to either previous infection or current infection which had been missed by histology. The rate of decline in serum antibodies after eradication of $H$ pylori with antimicrobial drugs is very variable, and antibody titres may remain high, compared with controls without gastritis, for years in some patients. ${ }^{27}$ More sensitive detection methods, such as use of the polymerase chain reaction, ${ }^{28}$ are required to determine whether low grade infection persists.

An important finding of our study is that risk factors for peptic ulceration in the elderly differ from those in younger patients. The incidence of $H$ pylori infection found on histological examination was no higher in the elderly patients with ulcers than those without, whereas use of NSAIDs was a feature in 19 of $30(63 \%)$ patients with ulcers compared with 22 of $82(27 \%)$ of those without. Eleven of the $15 \mathrm{H}$ pylori positive elderly patients with peptic ulceration were taking NSAIDs.

We conclude that the spectrum of gastritis is indeed different in the elderly, with a significantly higher incidence of $H$ pylori negative "non-specific" gastritis on histological examination. Detection of $H$ pylori by serology and histology may be less reliable in this age group. Explanations for the absence of $H$ pylori in gastritis include recent antibiotic intake, severe atrophy of the corpus mucosa, and infection missed by histology due to intestinal metaplasia or low bacterial density. Autoimmune gastritis was not an important factor. Furthermore, the association of $H$ pylori with peptic ulceration seen in younger adults is not a feature in this age group.

This study was undertaken with financial support from GistBrocades and the Yorkshire Regional Health Authority. We the ELISA and the staff of the Department of Gastroenterology 
of St James' University Hospital for their cooperation. Gastric autoantibodies were measured by Anne Batty and staff of the Immunology Department, St James' University Hospital.

1 Colin-Jones DG, Golding PL. What is a normal upper gastro-intestinal tract? BMF 1991;302:742.

2 Blaser MJ. Gastric Campylobacter-like organisms, gastritis and peptic ulcer disease. Gastroenterol 1987;93:371-83.

3 Graham DY, Klein PD, Opekun AR, et al. Epidemiology of Campylobacter pylori infection: Ethnic considerations. Scand F Gastroenterol 1988;23(suppl 142):9-13.

4 Dooley CP, Cohen H, Fitzgibbons PL, et al. Prevalence of Helicobacter pylori infection and histologic gastritis in Helicobacter pylori infection and histologic gastritis in

5 Wyatt JI, Dixon MF. Chronic gastritis-a pathogenetic approach. $\mathcal{f}$ Pathol 1988;154:113-24.

6 Stolte M, Heilmann KL. New classification of gastritis. Leger Magen Darm 1989;19:220-6.

7 Price AB. The Sydney system: histological division. $f$ Gastroenterol Hepatol 1991;6:209-22.

8 Crabtree JE, Shallcross TM, Wyatt JI, et al. Mucosal humoral immune response to Helicobacter pylori in patients with duodenitis. Dig Dis $S_{c i} 1991 ; 36: 1266-73$.

9 Crabtree JE, Mahony MJ, Taylor JD, et al. Immunoblotting and ELISA analysis of immune responses to Helicobacter pylori in children with recurrent abdominal pain. $₹$ Clin pylori in children with

10 Gray SF, Wyatt JI, Rathbone BJ. Simplified techniques for identifying Campylobacter pyloridis. $f$ Clin Patho 1986;39:1279-80

11 Sobala GM, King RFG, Axon ATR, Dixon MF. Reflux gastritis in the intact stomach. $f$ Clin Pathol 1990;43:303-6.

12 Dixon MF, Wyatt JI, Burke DA, Rathbone BJ. Lymphocytic gastritis - relationship to Campylobacter pylori infection. f Pathol 1988;154:125-32.

13 Shallcross TM, Rathbone BJ, Wyatt JI, Heatley RV. Helicobacter pylori associated chronic gastritis and peptic cobacter pylori associated chronic gastritis and peptic ulceration in patients taking non-steroidal anti-inflam
tory drugs. Aliment Pharmacol Ther 1990;4:515-22.

14 Wyatt JI, Rathbone BJ, Heatley RV. Local immune response to gastric Campylobacter in non-ulcer dyspepsia. $\mathcal{F} \mathrm{Clin}$ Pathol 1986;38:863-70.

15 Dixon MF. Campylobacter pylori and chronic gastritis. In Rathbone BJ, Heatley RV, eds. Campylobacter pylori and gastroduodenal disease Oxford: Blackwell Scientific Publications. 1989:106-16.

16 Wyatt JI, Primrose J, Dixon MF. Distribution of Campylobacter pylori in gastric biopsies. $\mathcal{f}$ Pathol 1988;155: $350 \mathrm{~A}$

17 Bayerdorffer E, Oertel H, Lehn N, et al. Topographic association between active gastritis and Campylobacter pylori colonisation. 7 Clin Pathol 1989;42:834-9.

18 Morris A, Ali MR, Brown P, Lane M, Patton K. Campylobacter pylori infection in biopsy specimens of gastric antrum: laboratory diagnosis and estimation of sampling antrum: laboratory diagnosis and

19 Karnes WE, Samloff IM, Siurala M, et al. Positive serum antibody and negative tissue staining for Helicobacter pylori in subjects with atrophic body gastritis. Gastroenterology

20 Feng T-L, Dooley CP, Dehesa M, et al. Helicobacter pylori infection in pernicious anaemia: a prospective controlled study. Gastroenterology 1991;100:328-32.

21 DeLuca VA. Is pernicious anaemia caused by Campylobacter pylori gastritis (letter). $\mathcal{f}$ Clin Gastroenterol 1989;11:584-5.

22 O'Connor HJ, Dixon MF, Wyatt JI, et al. Effect of duodenal ulcer surgery and enterogastric reflux on Campylobacter ulcer surgery and enterogastric ref
pyloridis. Lancet $1986 ; \mathrm{ii} ; 1178-81$.

23 Mainguet P, Delmee M, Debongnie J-C. Omeprazole, Campylobacter pylori and duodenal ulcer. Lancet Campylobacter

24 O'Riordan TG, Tobin A, O'Morain C. Helicobacter pylori infection in elderly dyspeptic patients. Age and Ageing 1991;20:189-92.

25 Crabtree JE, Shallcross TM, Heatley RV, Wyatt JI. Evaluation of a commercial ELISA for serodiagnosis of Helicobacter pylori infection. F Clin Pathol 1991;44: 326-38.

26 Horan MA, Fox RA. Ageing and the immune response--a unifying hypothesis. Mech Ageing Dev. 1984;26:165-81.

27 Newell DG, Bell GD, Weil J, et al. The effect of treatment of circulating anti-Helicobacter pylori antibodies-a twoyear follow-up study. In: Malfertheiner P, Ditschuneit H, year follow-up study. In: Malfertheiner $\mathrm{P}$, Ditschuneit $\mathrm{H}$, eds. Helicobacter pylori, gastritis

28 Ho S-A, Hoyle JA, Lewis FA, et al. A direct polymerase chain reaction test for the detection of Helicobacter pylor in humans and animals. F Clin Microbiol 1991;29. 2543-9. 